\title{
Isolation and Identification of Dibenzothiophene Desulfurizing Bacteria Occurring in Oil Contaminated Soils of Mechanical Workshops
}

\author{
Praveen Reddy $\mathrm{P}^{1}$ and UmaMaheswara Rao $\mathrm{V}^{2, *}$ \\ ${ }^{1}$ Department of Microbiology, Vivekananda Degree and PG College, Karimnagar-505001, Telangana, India; ${ }^{2}$ Department of Botany and \\ Microbiology, Acharya Nagarjuna University, Nagarjuna Nagar-522 510, Guntur District, Andhra Pradesh, India
}

Received: September 7, 2020; Revised: December 26, 2020; Accepted: January 7, 2021

\begin{abstract}
When fossil fuels are oxidized, a wide range of hazardous gases reach the atmosphere. Among these gases, sulfur oxides which are released because of oxidation of organosulfur compounds occurring in fuels become the sources of environmental pollution and acid rain. Hydrodesulfurization, a traditional practice employed for the removal of sulfur content from petroleum products during refining process is not eco-friendly and effective in removal of sulfur content, especially, recalcitrant organosulfur compounds like dibenzothiophene. Biodesulfurization, which employs microbes for the removal of sulfur from fossil fuels, is an eco-friendly method and a better alternative to hydrodesulfurization. The dibenzothiophene is treated as a model organosulfur compound for biodesulfurization studies. The present paper deals with the isolation of bacteria which exhibit dibenzothiophene biodesulfurization via 4S pathway from oil contaminated soils, detection of intermediates and end product of 4S pathway using Gas chromatography-Mass spectroscopy (GC-MS) in the DBT culture broths of isolates positive for gibb's test, amplification of $d s z$ operon genes which regulate 4S pathway in desulfurizing bacteria and identification of DBT desulfurizing bacteria by microscopic examination, biochemical tests and 16S rRNA gene anaylsis. Two DBT desulfurizing bacteria isolated were found positive for Gibb's test and Dibenzothiophene sulfone $\left(\mathrm{DBTO}_{2}\right)$, one of the intermediates and 2-Hydroxy biphenyl, the end product of 4S pathway were detected in DBT containing culture broths of both the desulfurizing bacteria when subjected to GC-MS. In both, the bacteria dsz operon genes were detected. The two bacteria were identified as Streptomyces sp. VUR PPR 101 and Streptomyces sp. VUR PPR 102.
\end{abstract}

Keywords: Biodesulfurization, Dibenzothiophene, 4S pathway, dsz operon, Streptomyces sp. VUR PPR 101, Streptomyces sp. VUR PPR 102

\section{Introduction}

The third most abundant element in fossil fuels is sulfur, and numerous organosulfur and sulfur containing inorganic compounds are present in fuels. When fossil fuels are oxidized, sulfur oxides reach the atmosphere (Bordoloi et al., 2016; Sadare et al., 2017) which are potent air pollutants and major source of acid rains ( $\mathrm{Li}$ et al., 2003). Sulfur dioxide in the environment causes health problems in humans like irritation of eyes, respiratory problems etc. (Wondyfraw, 2014). Even the plants that are exposed to sulfur dioxide exhibit change in their physiology and become susceptible to microbial infections. Prolonged exposure to sulfur dioxide increases rate of transpiration and dark respiration in plants (Khan and Khan, 2011). The conventional hydrodesulfurization (HDS) process used for the removal of sulfur from fossil fuels (petroleum products) which is operated at high temperature and pressure is not so effective in the elimination of sulfur from organosulfur compounds occurring in fossil fuels. Particularly, HDS is not effective in removal of sulfur from recalcitrant organosulfur compounds like Dibenzothiophene (DBT) (Wang et al.,
2017; da Silva and Secchi, 2018). To overcome the sulfur dioxide related problems, a new method involving microbes known as Biodesulfurization (BDS) has been developed to remove sulfur content from fossil fuels. The BDS is a very economical and eco-friendly process which does not make use of high temperature and pressure (Wang et al., 2017). For Biodesulfurization studies, DBT which is highly recalcitrant and hazardous is treated as model compound. The DBT is a very persistent compound as compared to most polyaromatic hydrocarbons (PAHs) and other aromatic hydrocarbons. It can remain for 10 years in crude oil polluted sediments, long after most aromatics have disappeared (Li et al., 2005; Mezcua et al., 2008). Microorganisms employ three major pathways for DBT metabolism viz., Kodama, Van Afferden and 4S pathways of which the $4 \mathrm{~S}$ pathway is regarded as commercially important one (de Araujo et al., 2012). The microbes which metabolize DBT via 4S pathway will not break the ring structure of DBT, and thus calorific value of fuel is unaffected. Specific interest was paid by researchers in isolating bacteria that specifically remove sulfur from organosulfur compounds without breaking the carbon backbone of the original organosulfur compounds. The $4 \mathrm{~S}$ pathway is such a metabolic pathway exhibited by certain

\footnotetext{
* Corresponding author e-mail: umrvanga@gmail.com.
} 
microbes during which sulfur element is removed as sulfite from DBT without affecting its ring structure (Labana et al., 2005). The DBT metabolism via other pathways may result in cleavage of DBT ring or sulfur is not removed. Hence, microbes which exhibit 4S pathway for the desulfurization of DBT are eco-friendly and economically important. Various microbes which exhibit 4S pathway include Rhodococcus erythropolis XP, Rhodococcus erythropolis IGTS8, Gordonia alkanivorans RIPI90A etc. (de Araujo et al., 2012; Bordoloi et al., 2016). The 4S pathway is a multienzymatic system with four different activities (Gray et al., 1996). First enzyme of the 4S pathway is monooxygenase (DszC) which catalyzes the DBT oxidation to Dibenzothiophene sulfone $\left(\mathrm{DBTO}_{2}\right)$ in two steps. The second is also a monooxygenase (DszA) which converts $\mathrm{DBTO}_{2}$ to Hydroxyphenyl benzene sulfonate (HPBS), and in the final step DszB (HPBS desulfinase) converts HPBS to 2-hydroxy biphenyl (2HBP) and sulfite. In this metabolic pathway, FMNreductase (DszD) has an important role in the activity of the monooxygenases, as it is responsible for the maintenance of reduced flavin levels. The $d s z A, B$ and $C$ genes of $d s z$ operon synthesize DszA, DszB and DszC enzymatic proteins, respectively (Muraka et al., 2019). The microbial cells have been majorly exploited in pharmaceutical and food industries to produce antibiotics, vitamins, amino acids, alcoholic beverages etc., on large scale. Even various microbial strains are employed in reclamation of polluted sites (bioremediation) and treatment of used engine oils. The biocatalytic desulfurization of fuels is an important and useful emerging process in the present-day context in view of curbing the environmental pollution. The biodesulfurizing microbial strains could pave the way for effective desulfurization process and can be employed in future to generate sulfur free fuels. In the present work, an attempt was made to isolate bacterial strains exhibiting DBT biodesulfurization via 4S pathway using Gibb's assay and by detecting the intermediates and end product of $4 \mathrm{~S}$ pathway in DBT containing culture broth using Gas chromatography-Mass spectroscopy (GC-MS), identification of $d s z$ operon genes responsible for $4 \mathrm{~S}$ pathway using specific primers and identification of the positive DBT desulfurizing bacteria based on morphological and microscopic examination, biochemical tests and 16S rRNA gene sequencing.

\section{Materials and Methods}

\subsection{Isolation of bacteria growing in DBT supplemented medium}

To isolate Dibenzothiophene desulfurizing bacteria, different mechanical workshop sites in Karimnagar town, Telangana, India were selected and designated as A, B, C, D, E and F. Heavy motor vehicles in workshops A and B, light motor vehicles in workshops $\mathrm{C}$ and $\mathrm{D}$, and two wheelers in workshops $\mathrm{E}$ and $\mathrm{F}$ are repaired and serviced. From these sites, oil contaminated soil samples were collected bimonthly for a period of one year. For the isolation of DBT-desulfurizing bacteria, ten grams of each soil sample was suspended in $90 \mathrm{ml}$ of distilled water and $5 \mathrm{ml}$ of the suspension was inoculated into $250 \mathrm{ml}$ flask containing $45 \mathrm{ml}$ of basal salt medium (BSM) supplemented with glucose $(5 \mathrm{~g} / \mathrm{l})$ as carbon source and 5
$\mathrm{mM}$ per liter DBT as sole sulfur source. Cultivation was performed at $30^{\circ} \mathrm{C}$ in rotary shaker for 5 days. After five sub cultivations, the culture broth medium was spread onto BSM agar medium supplemented with glucose and DBT (Khedkar and Shanker, 2014). All the viable and dominantly growing representative bacterial cultures were isolated from samples of Workshops.

$$
\text { 2.2. Gibb's assay }
$$

The recovered cultures were grown in BSM broth supplemented with glucose and DBT and tested for the occurrence of $4 \mathrm{~S}$ pathway within them by detecting 2-HBP, the end product of $4 \mathrm{~S}$ pathway by the Gibb's assay. The test was used to detect the 2HBP produced by the bacteria after growing them in the medium containing DBT. Gibb's reagent reacts with aromatic hydroxyl groups such as 2-hydroxy phenyl to form blue colored complex. The $\mathrm{pH}$ of bacterial culture broths was adjusted to 8.0 using $10 \%$ sodium bicarbonate or sodium carbonate and $100 \mathrm{\mu l}$ of Gibb's reagent $(10 \mathrm{mg}$ of 2,6dichlorquinone-4-chlorimide prepared in $1 \mathrm{ml}$ of ethanol) was added to $5 \mathrm{ml}$ of each bacterial culture broth and incubated for 30 minutes. Formation of blue color complex indicates the positive result and brown color indicates negative result for Gibb's assay. The cultures positive for Gibb's assay were expected to produce 2-HBP via 4S pathway from DBT (Kayser et al., 1993).

\subsection{GC-MS analysis of DBT culture broths of bacteria positive for Gibb's test}

The culture broth was centrifuged and the supernatant was acidified with $6 \mathrm{~N}$ hydrochloric acid to $\mathrm{pH}$ 2.0. The acidified supernatant was mixed with equal volume of ethyl acetate, and the extracted samples were subjected to GC-MS analysis. The GC-MS instrument employed was an Agilent 7890A model in which GC was coupled with a Pegasus HT TOFMS. The specifications of GC column include $29.8 \mathrm{~m}$ x $0.2 \mu \mathrm{m}$ and $0.2 \mathrm{~m}$ x $320 \mu \mathrm{m}$. The initial and final temperatures employed for sample analysis were $60^{\circ} \mathrm{C}$ and $320^{\circ} \mathrm{C}$, respectively. The rate of increase of temperature during sample analysis was $15^{\circ} \mathrm{C}$ per minute. The temperature maintained during the entire sample run was $280^{\circ} \mathrm{C}$. Helium was used as carrier gas with a flow rate of $1.2 \mathrm{ml}$ per minute to run $1 \mu \mathrm{l}$ of DBT culture broth sample.

\subsection{Identification of dsz operon genes responsible for $4 S$} pathway

The forward and reverse primers used for the amplification of $d s z A$ gene were 5'GCGCGGCAAGTTCGATCTGT-3' and 5'TCCCGCAGGATGTCCTTGATC-3', respectively. The primers used for the amplification of $d s z B$ gene were 5'-ATCGAACTCGACGTCCTCAG-3' (forward) and 5'-TCAGGACCACAGCTACAAGG3 ' (reverse). For the amplification of $d s z C$ gene, the forward and reverse primers employed were 5'CTGTTCGGATACCACCTCAC-3' and 5'GTGCCTGAAGGTGTTGCA-3', respectively (Duarte et al., 2001; Li et al., 2007). 


\subsection{Identification of bacterial isolates}

\subsubsection{Colony characteristics}

Colony characteristics of the bacterial isolates positive for DBT desulfurization via 4S pathway were observed on DBT containing basal salt medium. The color, configuration, elevation, margin and size of the colonies were recorded.

\subsubsection{Microscopic examination and Biochemical tests}

Gram staining and spore staining of the DBT desulfurizing bacteria were performed and the morphological shapes were also noticed. The biochemical tests viz., starch hydrolysis, casein hydrolysis, sucrose test, catalase test, oxidase test, hydrogen sulfide production, lipid activity, indole test, methyl red test, Voges-Proskaeur test, citrate utilization test, urea hydrolysis test and nitrate reduction test were performed as per the standard procedures (Kim et al., 2001; Reddy et al., 2011; Bennett et al., 2018).

\subsubsection{S rRNA sequencing and phylogenetic analysis of} the bacterial isolates

The 16s rRNA sequencing and phylogenetic analysis of the bacterial isolates positive for DBT desulfurization were carried out at Bioaxis DNA Research Centre (BDRC), Hyderabad for the identification. The primers used for the amplification of 16S rRNA gene were 5'GCAATAACAGGTCTGTGATGCCC-3' (forward) and 5'-GCATCACAGACCTGTTATTGC-3' (reverse) (Frank et al., 2008).

\subsection{Isolation of chromosomal DNA}

The cultures of B39 and B40 were transferred separately into $50 \mathrm{ml}$ BSM broth supplemented with glucose and dibenzothiophene taken in $250 \mathrm{ml}$ flasks and incubated in a shaker at $30^{\circ} \mathrm{C}$ at $180 \mathrm{rpm}$ for 4 days. After incubation period, the culture broths were subjected to centrifugation at $10,000 \mathrm{rpm}$ for ten minutes. Then 0.1 grams of mycelium of each isolate was crushed with liquid nitrogen in a clean porcelain dish. Then crushed mycelium of each isolate was transferred to a tube consisting of 500 $\mu \mathrm{l}$ TE buffer containing lysozyme enzyme and incubated for half an hour at $37^{\circ} \mathrm{C}$. Then, $20 \mu \mathrm{l}$ SDS (10\%) and $20 \mu \mathrm{l}$ proteinase $\mathrm{K}$ were added, and the tube was incubated for thirty minutes at $55^{\circ} \mathrm{C}$. After incubation period, the mixture was cooled and centrifuged at 10,000 rpm for five minutes and extracted with phenol-chloroform (1:1) solution. The aqueous phase of the mixture was taken in clean tube and DNA precipitate was obtained by using $90 \%$ ethyl alcohol at $-20^{\circ} \mathrm{C}$. Then DNA pellet was recovered after centrifuging for ten minutes at 10,000 rpm. The pellet was dissolved in TE buffer and $20 \mu \mathrm{l}$ of RNase enzyme was added and incubated at $37^{\circ} \mathrm{C}$ for one hour to get RNA free DNA. The DNA is again precipitated by using $90 \%$ ethyl alcohol at $-20^{\circ} \mathrm{C}$. Then, pure DNA pellet was obtained by centrifugation (at 10,000 rpm for 10 minutes) (Kumar et al., 2010), and the purity of DNA was determined by using UV spectrophotometer.

\subsection{PCR amplifications}

The PCR mixture containing $200 \mu \mathrm{M}$ dNTPs, $100 \mathrm{ng}$ of genomic DNA, 6 mM magnesium chloride, 10\% dimethyl sulfoxide, each primer of 30 pmol and 2.5 units of Taq Pol. in $50 \mu$ l buffer was prepared. The amplification was performed by initially increasing the temperature of mixture to $94^{\circ} \mathrm{C}$ for 1 minute (denaturation), then decreased to $57^{\circ} \mathrm{C}$ for 60 seconds (annealing) and increased to $72^{\circ} \mathrm{C}$ for 1 minute (extension of hybridized primers), followed by final extension at $72^{\circ} \mathrm{C}$ for 5 minutes in thirty-five cycles. Then the PCR reaction mixture was subjected to agarose gel electrophoresis by employing a size marker of $1 \mathrm{~kb}$ DNA ladder. The dideoxy chain termination procedure was used for the sequencing of rRNA genes (Kurnijasanti et al., 2017). The $16 \mathrm{~S}$ rRNA gene sequences of B39 and B40 isolates were submitted to NCBI Genbank. Further, neighbor joining method was employed for the construction of phylogenetic trees of the isolates.

\section{Results and Discussion}

\subsection{Isolation of predominantly growing bacteria on DBT containing medium and screening for bacterial strains positive for Gibb's test}

In the present work, a total of 46 predominantly growing bacterial representative types on BSM medium supplemented with DBT were obtained from oil contaminated sites of different mechanical workshops. On screening, all these isolates for the presence of $4 \mathrm{~S}$ pathway metabolic activity through Gibbs assay, only two bacteria (designated as B39 and B40) isolated from the soil of mechanical workshop B were found positive for 4S pathway. This was confirmed by the development of blue coloration during Gibbs assay indicating the production of 2-HBP which is the end product of 4S pathway (Rahpeyma et al., 2017). The Gibb's assay was used to identify the desulfurization activity of bacteria through $4 \mathrm{~S}$ pathway by several earlier workers (Sadare et al., 2017; Shahaby and El-din, 2017; Li et al., 2019). The other isolates of our study which were negative for Gibb's assay may be utilizing the other pathways viz., Kodama pathway and Van Afferden pathway for metabolizing DBT as they were also grown abundantly on basal salt medium supplemented with glucose and DBT as sole sulfur source.

3.2. Detection of intermediates and the end product of $4 S$ pathway by GC-MS

The two Gibb's test positive bacterial isolates (B39 and B40) were subjected to GC-MS analysis for the detection of metabolites of 4S pathway. In GC-MS analysis of B39 isolate culture broth, the compounds with retention time of 13.6117 and 9.22667 minutes were identified as DBT sulfone and the 2-HBP, respectively (Figure 1). Similarly, GC-MS of B40 culture broth showed the presence of the same compounds with retention time of 13.61 and 9.23167 minutes that were identified as DBT sulfone and 2-HBP, respectively (Figure 2). Li et al. (2003) have detected DBT sulfone and 2-HBP by GC-MS in the DBT culture broth of Mycobacterium sp. X7B. Similarly, Rhee et al. (1998) during their DBT desulfurizing studies with newly isolated Gordona strain CYKS1, observed DBT sulfone and 2HBP in the GC chromatogram of DBT culture broth. In the mass spectrum of DBT sulfone pertaining to B39 isolate, a molecular $\left[\mathrm{M}^{+}\right]$ion peak at $\mathrm{m} / \mathrm{z} \quad 216$ was found corresponding to the molecular mass of DBT sulfone and the major fragmentation ions were seen at $\mathrm{m} / \mathrm{z} 139$ and 63 (Figure 3). Similarly, in the mass spectrum of 2-HBP of B39, a molecular $\left[\mathrm{M}^{+}\right]$ion peak at $\mathrm{m} / \mathrm{z} 170$ was observed corresponding to the molecular mass of 2-HBP and the major fragmentation ions were seen at $m / z$ 141,115 and 63 
(Figure 4). In the mass spectrum of DBT sulfone of B40 isolate, a molecular $\left[\mathrm{M}^{+}\right]$ion peak at $\mathrm{m} / \mathrm{z} 216$ was noticed corresponding to the molecular mass of DBT sulfone and the major fragmentation ions were seen at $\mathrm{m} / \mathrm{z} 187,136$ and 63 (Figure 5). Similarly, in the mass spectrum of 2HBP of B40, a molecular $\left[\mathrm{M}^{+}\right]$ion peak at $\mathrm{m} / \mathrm{z} 170$ was found corresponding to the molecular mass of 2-HBP and the major fragmentation ions were seen at $m / z$ 141,115, 89 and 63 (Figure 6). This observation is in great concurrence with several earlier reports in this aspect (Mohebali et al., 2008; Mohammed et al., 2015; Ismail et al., 2016). Even, Akhtar et al. (2009) also detected similar molecular ion peaks of DBT sulfone and 2-HBP in the mass spectra of DBT culture broths of Rhodococcus species, when subjected to GC-MS.

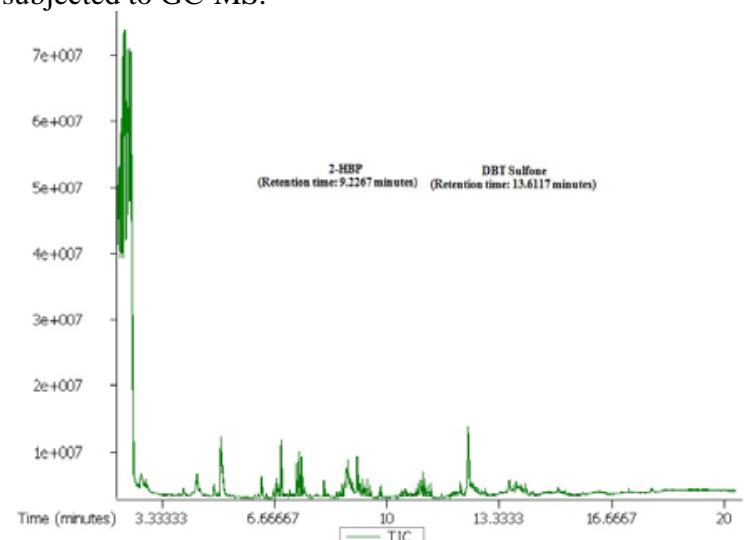

Figure 1. Gas Chromatogram of DBT broth extract of the bacterial isolate B39

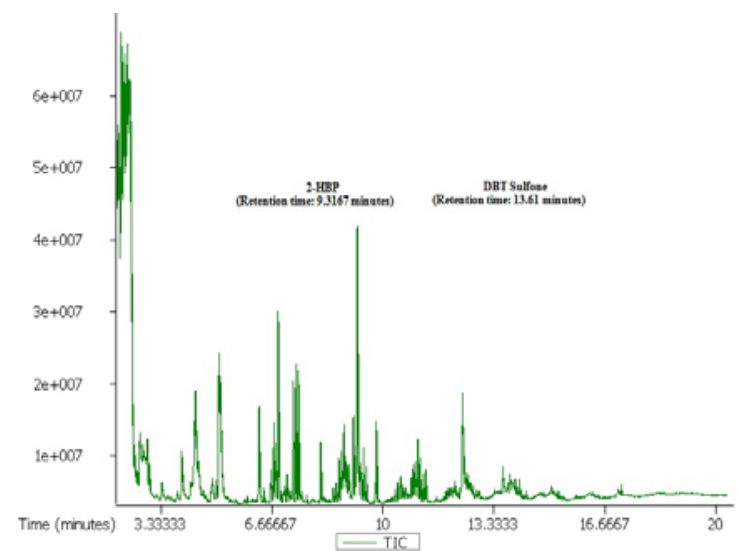

Figure 2. Gas Chromatogram of DBT broth extract of bacterial isolate B40

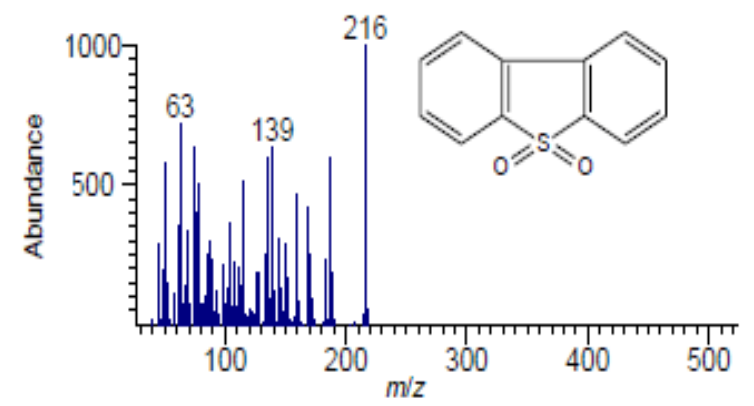

Figure 3. Mass spectrum of DBT sulfone of the bacterial isolate B39

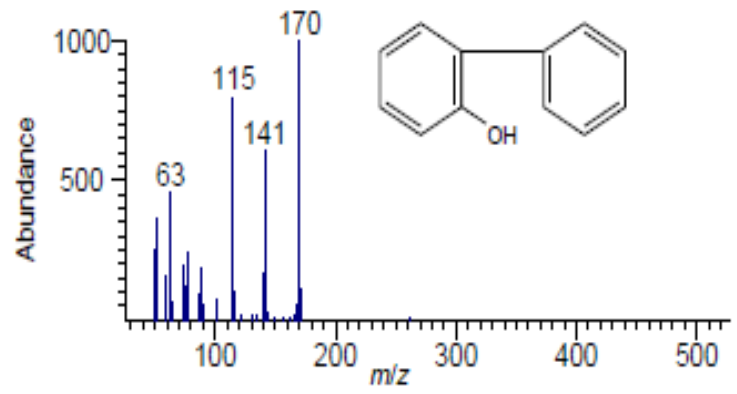

Figure 4. Mass spectrum of 2-HBP of the bacterial isolate B39

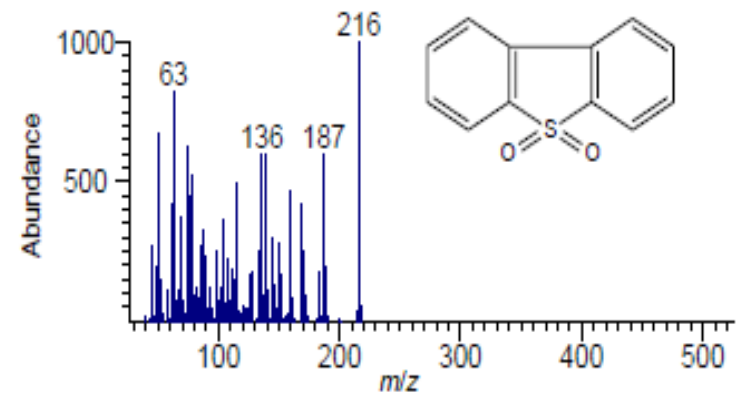

Figure 5. Mass spectrum of DBT sulfone produced by bacterial isolate B40

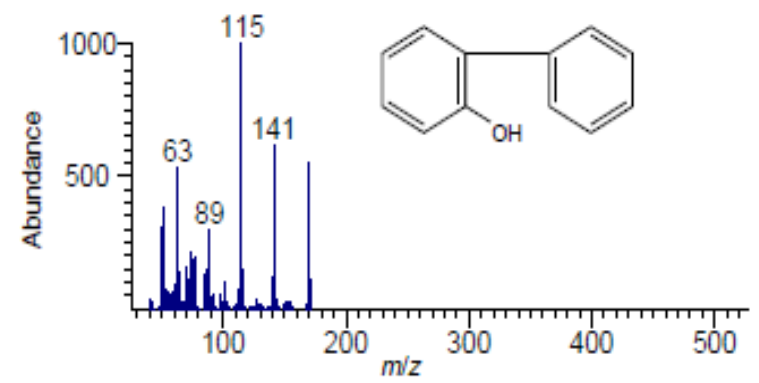

Figure 6. Mass spectrum of 2-HBP produced by bacterial isolate B40

\subsection{Amplification of dsz operon genes in DBT desulfurizing bacteria}

In both the bacterial isolates, $d s z A B C$ operon genes were amplified (Figure 7) indicating their presence. Interestingly, the $d s z$ operon in both the isolates was located on genomic DNA, which has good concurrence with earlier report of Shavandi et al. (2010) who identified the presence of $d s z$ operon genes responsible for DBT desulfurization on chromosome in Gordonia alkanivorans RIPI90A. However, in Rhodococcus erythropolis IGTS8 strain, which is a model strain for biodesulfurization studies, the $d s z$ operon was reported to be present on plasmid. 


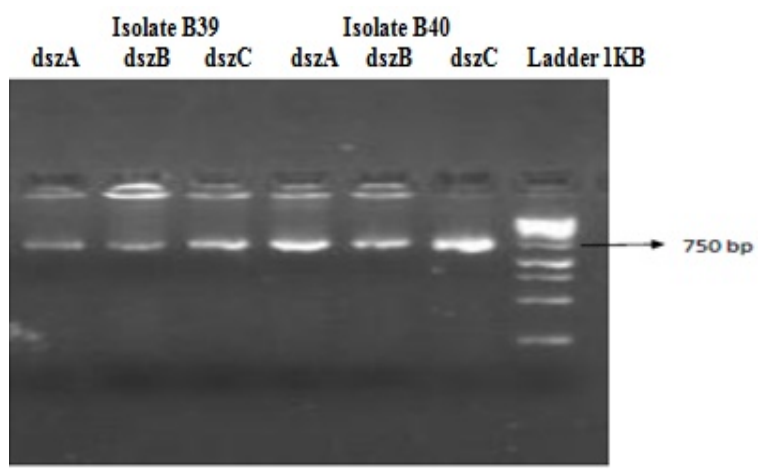

Figure 7. PCR gel picture of amplified $d s z$ operon genes of the B39 and B40 bacterial isolates

\subsection{Identification of bacteria positive for DBT desulfurization via $4 S$ pathway}

Based on colony characteristics (Table 1), morphological (shape), staining (Gram's and Spore) and biochemical studies viz., starch hydrolysis, casein hydrolysis, sucrose test, catalase test, oxidase test, hydrogen sulfide production, lipid activity, indole test, methyl red, Voges-Proskaeur test, citrate utilization test, urea hydrolysis and nitrate reduction test (Table 2), the two desulfurizing bacteria are identified as Gram positive, filamentous and tentatively as Streptomyces species. Taddei et al. (2006) based on the similar morphological and biochemical studies, identified bacteria isolated from Venezuelan soils as Streptomyces species.

Table 1. Colony characteristics of the bacterial isolates

\begin{tabular}{lll}
\hline Colony character & B39 isolate & B40 isolate \\
\hline Color & White & Light grey \\
Configuration & Round & Round \\
Elevation & Convex & Convex \\
Margin & Ciliate & Ciliate \\
Size (Diameter) & $4.2 \mathrm{~mm}$ & $3.5 \mathrm{~mm}$ \\
\hline
\end{tabular}

Table 2. Morphological, Gram staining, Spore shape and Biochemical tests.

\begin{tabular}{lll}
\hline Characteristics & \multicolumn{2}{l}{ Bacterial isolates } \\
\cline { 2 - 3 } Microscopic observation & B39 & B40 \\
Morphological shape & Filamentous & Filamentous \\
Gram staining & Gram positive & Gram positive \\
Spore shape & Oval to circular & Oval \\
Biochemical tests & & \\
Starch hydrolysis & Positive & Positive \\
Casein hydrolysis & Positive & Positive \\
Sucrose test & Positive & Positive \\
Catalase test & Positive & Positive \\
Oxidase test & Positive & Positive \\
H ${ }_{2}$ S Production test & Positive & Positive \\
Citrate utilization test & Positive & Positive \\
Lipid activity & Positive & Positive \\
Indole test & Negative & Negative \\
Methyl red test & Positive & Positive \\
Voges-Proskaeur test & Negative & Negative \\
Urea hydrolysis & Positive & Positive \\
Nitrate reduction test & Positive & Positive \\
\hline
\end{tabular}

The 16S rRNA genes of both the bacterial isolates were amplified using the standard primers and sequenced. The partial length of rRNA gene sequences of bacterial isolates, B39 and B40 were 1,393 and 1,395, respectively. The phylogenetic analysis revealed that B39 and B40 were closely related to Streptomyces sp. SPMA113 (Accession No. HQ340163.1) and Streptomyces sp. Antag6 (Accession No. JQ417273.1), respectively (Figure 8). The percentage of identity between the Streptomyces species was determined using NCBI BLASTn tool. The percentage of identity between B39 and Streptomyces sp. SPMA113 was found to be $100 \%$. Similarly, the percentage of identity between B40 and Streptomyces sp. Antag6 was also $100 \%$. There was $98.91 \%$ of identity between B39 and B40 isolates. The rRNA gene proved to be a universal tool for the phylogenetic analysis and interrelation among the organisms as it is ancient, universally distributed and most conserved region in the genome of the microorganisms. Although there are three different ribosomal RNAs i.e., 5S, $16 \mathrm{~S}$ and $23 \mathrm{~S}$ in prokaryotes, only $16 \mathrm{~S}$ rRNA sequence is used because the nucleotides in $16 \mathrm{~S}$ rRNA are neither less nor more in length and easy to sequence. The rRNA sequence is used to construct phylogenetic tree by applying distance-matrix method. The evolutionary distance is determined by recording differences in the sequences of two or more organisms by software computer analysis. A statistical correction factor is applied due to the reason that some changes might have taken place in the genome which would lead back to the same sequence. After measuring the evolutionary distance, the phylogenetic tree is constructed. The different evolutionary distances of the two microorganisms are directly proportional to the total length of the branches separating them. Depending on software/computer program and the number of microorganisms, different formats of phylogenetic trees are possibly constructed (Chapus et al., 2005). The gene sequences were submitted to NCBI Genbank designating B39 and B40 isolates as Streptomyces sp. VUR PPR101 and Streptomyces sp. VUR PPR 102, respectively. The Genbank had accepted and given the accession numbers, KF551242.1 and KF551243.1 to Streptomyces sp. VUR PPR 101 and Streptomyces sp. VUR PPR 102, respectively.

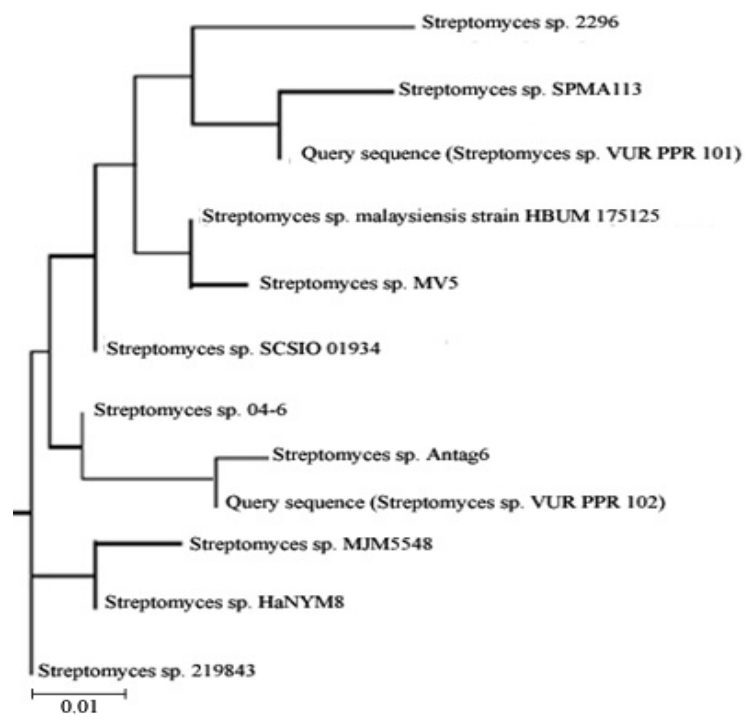


Figure 8. Phylogenetic analysis of Streptomyces sp. VUR PPR 101and Streptomyces sp. VUR PPR 102.

The scale bar infers $1 \%$ of the estimated nucleotide difference.

The Streptomyces species isolated in the present work are aerobic in nature and obviously exhibiting the aerobic DBT desulfurization (4S) pathway. Therefore, they will be commercially and economically important when compared to microbial strains exhibiting anaerobic biodesulfurization pathways. When microbial strains exhibiting oxidative DBT desulfurization pathway are employed during oil refining process, they form water soluble sulfite from DBT which can be easily disposed by employing an aqueous phase. On the other hand, anaerobic desulfurization occurs by a reductive pathway during which sulfur from DBT is removed as hydrogen sulfide which later releases sulfur atom. Though the anaerobic strains can be employed for desulfurization, it is a difficult and costly affair to maintain anaerobic conditions throughout the process, moreover it is time consuming and undesirable products may form from organic constituents of fuels (Sadare et al., 2017). Further, there is a scope to genetically modify these Streptomyces species for enhanced DBT biodesulfurization activity. Such genetically improved biodesulfurizing Streptomyces strains can be commercially important and potent to employ in desulfurization of fuels during refining process to produce sulfur free fuel products.

\section{Conclusion}

In the present study, two potential DBT desulfurizing Streptomyces species were isolated from oil contaminated soils of mechanical workshops. Both the desulfurizing species are commercially important as they showed the ability to desulfurize the DBT occurring in fuels, the model compound for biocatalytic desulfurization studies by 4S pathway without breaking the ring structure of DBT and not leading to the reduction of calorific value of fuel (mileage). The $d s z$ operon genes $(A, B$ and $C$ ) responsible for $4 \mathrm{~S}$ pathway were identified in both the Streptomyces species. These two DBT desulfurizing Streptomyces species gain ecological and commercial importance in Biodesulfurization of fuels.

\section{Acknowledgments}

Both the authors of this manuscript convey thanks to the Department of Botany and Microbiology, Acharya Nagarjuna University, Guntur for the support and facilities provided to carry out the research work.

\section{Conflict of interests}

The authors declare that they have no conflict of interests.

\section{References}

Akhtar N, Ghauri MA, Anwar MA and Akhtar K. 2009. Analysis of the dibenzothiophene metabolic pathway in a newly isolated Rhodococcus spp. FEMS Microbiol Lett., 301(1): 95-102.

Bennett JA, Kandell GV, Kirk SG and McCormick JR. 2018. Visual and microscopic evaluation of Streptomyces developmental mutants. J. Vis. Exp., 139: e57373.

Bordoloi NK, Bhagowati P, Chaudhuri MK and Mukherjee AK. 2016. Proteomics and metabolomics analyses to elucidate the desulfurization pathway of Chelatococcus sp. PLoS One., 11: e0153547.

Chapus C, Dufraigne C, Edwards S, Giron A, Fertil B and Deschavanne P. 2005. Exploration of phylogenetic data using a global sequence analysis method. BMC Evol Biol., 5: 63.

da Silva JIS and Secchi AR. 2018. An approach to optimize costs during ultra-low hydrodesulfurization of a blended consisting of different oil streams. Braz. J. Chem. Eng., 35(4): 1293-1304.

de Araujo HWC, de Freitas SMC, Lins CM, do Nascimento AE, da Silva CAA and Compos-Takaki GM. 2012. Oxidation of dibenzothiophene (DBT) by Serratia marcescens UCP 1549 formed biphenyl as final product. Biotechnology for Biofuels., 5: 33.

Duarte GF, Rosado AS, Seldin L, Araujo W and Van Elsas JD. 2001. Analysis of bacterial community structure in sulfurous-oilcontaining soils and detection of species carrying dibenzothiophene desulfurization (dsz) genes. Appl Environ Microbiol., 67(3): 1052-1062.

Frank JA, Claudia IR, Sharma S, Weisbaum JS, Wilson BA and Olsen GJ. 2008. Critical Evaluation of two primers commonly used for amplification of bacterial 16S rRNA genes. Appl. Environ. Microbiol., 74(8): 2461-2470.

Gray KA, Pogrebinsky OS, Mrachko GT, Xi L, Monticello DJ and Squires CH. 1996. Molecular mechanisms of biocatalytic desulfurization of fossil fuels. Nat Biotechnol., 14(13): 17051709.

Ismail W, El-Sayed WS, Raheem ASA, Mohamed ME and El Nayal AM. 2016. Biocatalytic desulfurization capabilities of a mixed culture during non-destructive utilization of recalcitrant organosulfur compounds. Front Microbiol., 7: 266.

Kayser KJ, Bielaga-Jones BA, Jackowski K, Odusan O and Kilbane II JJ. 1993. Utilization of organosulphur compounds by axenic and mixed cultures of Rhodococcus rhodochrous IGTS8. J. Gen. Microbiol,, 139(12): 3123-3129.

Khan MR and Khan MM. 2011. Plants response to diseases in sulfur dioxide stressed environment. Plant Pathol. J., 10(1): 1-12.

Khedkar S and Shanker R. 2014. Isolation and classification a soil actinomycete capable of sulphur- specific biotransformation of diebenzothiophene, benzothiophene and thianthrene. J. Appl. Microbiol., 118(1): 62-74.

Kim EK, Jang WH, Ko JH, Jong SK, Kang JS, Noh MJ and Yoo OJ. 2001. Lipase and its modulator from Pseudomonas sp. strain KFCC 10818: Proline-to glutamine substitution at position 112 induces formation of enzymatically active lipase in the absence of the modulator. J Bacteriol., 183(20): 5937-5941.

Kumar V, Bharti A, Gusain O and Bhist GS. 2010. An improved method for isolation of genomic DNA from filamentous actinomycetes. Journal of Sci. Engg. \& Tech. Mgt., 2(2): 10-13.

Kurnijasanti R, Isnaeni, Poernomo AT and Sudjarwo. 2017. Phylogenetic analysis and anti microbial activity of Streptomyces spp. Isolated from compost soil in Surabay Indonesia on the basis of 16S rRNA gene. Folia Medica Indonesiana., 53(3): 204-208. 
Labana S, Pandey G and Jain RK 2005. Desulfurization of dibenzothiophene and diesel oils by bacteria. Lett Appl Microbiol., 40(3): 159-163.

Li FL, Xu P, Ma CQ, Luo LL and Wang XS. 2003. Deep desulfurization of hyrodesulfurization treated diesel oil by a facultative thermophilic bacterium Mycobacterium sp. X7B. FEMS Microbiol Lett., 223(2): 301-307.

Li GQ, Ma T, Li SS, Li H, Liang FL and Liu RL. 2007. Improvement of dibenzothiophene desulfurization activity by removing the gene overlap in the $d s z$ operon. Biosci Biotechnol Biochem., 71(4): 849-854.

Li L, Liao Y, Luo Y, Zhang G, Liao X, Zhang W, Zheng S, Han S, Lin Y and Liang S. 2019. Improved efficiency of desulfurization of oil sulfur compounds in Escherichia coli using a combination of desensitization engineering and DszC overexpression. ACS Synth. Biol., 8(6): 1441-1451.

Li W, Zhang Y, Wang MD and Shi Y. 2005. Biodesulfurization of dibenzothiophene and other organic sulfur compounds by a newly isolated Microbacterium strain ZD-M2. FEMS Microbiol Lett., 247(1): 45-50.

Mezcua M, Fernandez-Alba AR, Boltes K, Alonso Del Aquila R, Leton P, Rodriquez A and Garcia-Calvo E. 2008. Determination of PASHs by various analytical techniques based on gas chromatography-mass spectrometry: Application to a biodesulfurization process. Talanta., 75(5): 1158-1166.

Mohammed MES, Yacoub ZHA and Vedakumar JV. 2015 Biocatalytic desulfurization of thiophenic compounds and crude oil by newly isolated bacteria. Front Microbiol., 6: 112.

Mohebali G, Ball AS, Kaytash A and Rasekh B. 2008. Dimethy sulfoxide (DMSO) as the sulfur source for the production of desulfurizing resting cells of Gordonia alkanivorans RIPI90A. Microbiology., 154(3): 878-885.

Muraka P, Bagga T, Singh P, Rangra S and Srivastava P. 2019. Isolation and identification of TetR family protein that regulates the biodesulfurization operon. AMB Expr., 9: 71.
Rahpeyma SS, Mohammadi M and Raheb J. 2017. Biodesulfurization by two bacterial strains in cooperation with $\mathrm{Fe}_{3} \mathrm{O}_{4}, \mathrm{ZnO}$ and $\mathrm{CuO}$ nanoparticles. J Microb Biochem Technol., 9(2): 587-591.

Reddy NG, Ramakrishna DPN and Raja Gopal SV. 2011. A morphological, physiological and biochemical studies of marine Streptomyces rocheri (MTCC 10109) showing antagonistic activity against selective human pathogenic microorganisms. Asian J. Biol. Sci., 4(1): 1-14.

Rhee SK, Chang JH, Chang YK and Chang HN. 1998. Desulfurization of dibenzothiophene and diesel oils by a newly isolated Gordona strain, CYKS1. Appl. Environ. Microbiol., 64(6): 2327-2331.

Sadare OO, Obazu F, Rasekh B and Daramola MO. 2017. Biodesulfurization of petroleum distillates - Current status, opportunities and future challenges. Environments., 4(4): 85.

Shahaby AF and El-din KME. 2017. Desulfurization of crude oil and oil products by local isolated bacterial strains. Int. J. Curr. Microbiol. App. Sci., 6(4): 2695-2711.

Shavandi M, Sadeghizadeh M, Khajeh K, Mohebali G and Zomorodipour A. 2010. Genomic structure and promoter analysis of the dsz operon for dibenzothiophene biodesulfurization from Gordonia alkanivorans RIPI90A. Appl Microbiol Biotechnol., 87(4):1455-1461.

Taddei A, Rodriguez MJ, Marquez-Vilchez E and Castelli C. 2006. Isolation and identification of Streptomyces spp. From Venezuelan soils: Morphological and biochemical studies. I. Microbiol Res., 161(3): 222-231.

Wang J, Butler III RR, Wu F, Pomber JF, Kilbane II JJ and Stark BC. 2017. Enhancement of microbial biodesulfurization via genetic engineering and adaptive evolution. PLoS One., 12: e0168833.

Wondyfraw M. 2014. Mechanisms and effects of acid rain on environment. J Earth Sci Clim Change., 5(6): 204. 